\title{
Acute toxic dilatation of the colon in Crohn's colitis
}

\author{
A. J. BUZZARD, W. N. W. BAKER, P. R. G. NEEDHAM, AND R. E. WARREN
}

From the Gordon Hospital, London

SUMmaRY Twelve new cases of acute toxic dilatation of the colon in Crohn's colitis treated by total colectomy and ileorectal anastomosis are reported, and criteria for making the diagnosis are given.

The complication has occurred in $6 \%$ of patients diagnosed as having Crohn's disease of the colon treated at the Gordon Hospital since 1948. The patients have been predominantly young adult females, with a short preoperative history of disease. The sigmoidoscopic appearance of the rectum preoperatively has been no indication of the likelihood of recurrent disease at the anastomosis. Only four patients still have successfully functioning ileorectal anastomoses and four patients have died from the effects of the disease.

Acute toxic dilatation of the colon has been recognized as a complication of ulcerative colitis for many years (Lumb, Protheroe, and Ramsay, 1955; Roth, Valdes-Dapena, Stein, and Bockus, 1959; Morson and Dawson, 1972) but its occurrence in Crohn's colitis has not been described until recently. We know of only 11 cases of acute toxic dilatation of the colon in Crohn's colitis with reasonably full clinical and pathological details (Schachter, Goldstein, and Kirsner, 1967; McGovern and Goulston, 1968; Javett and Brooke, 1970; Leoutsakos and Pedridis, 1970; Papp and Pollard, 1970; Clark, 1972), and of 18 others without full descriptions (Farmer, Hawk, and Turnbull, 1968; Fielding and Truelove, 1972; Brooke, 1972).

The objects of this paper are: (1) to define the condition on clinical and pathological criteria; (2) to report 12 further cases treated surgically by total colectomy and ileorectal anastomosis; and (3) to assess the results of treatment.

\section{Materials and Methods}

The case records of all patients with ulcerative colitis and Crohn's disease of the colon seen in the Gordon Hospital between 1948 and 1972 were reviewed by two of us (A.J.B. and W.N.W.B.), and those patients who presented with acute toxic dilatation of the colon were selected for further study. All these patients had undergone emergency total colectomy, and photographs of the gross colectomy specimens, together with histological sections taken at standard sites from each specimen (Dawson and Pryse-Davies, 1959), were reviewed by two of us (P.R.G.N. and R.E.W.). Each case was classified as either ulcerative colitis or Crohn's disease on the basis of antecedent history, clinical presentation, and the gross and histopathological appearances of the colectomy specimens using current criteria (Morson and Dawson, 1972). In addition, the maximum width of the transverse colon in the opened-out, formalinfixed state was measured from each photograph using the scale adjacent to the specimen in the photograph (see fig).

\section{DEFINITIONS}

The following criteria were applied to each case accepted as acute toxic dilatation of the colon.

Acute

All patients should be ill and showing a rapid deterioration in their general health.

Toxic

At least two of the following measurements should apply in the 48 hours immediately preceding operation (adapted from Truelove and Witts, 1955; Roth et al, 1959): (1) an oral temperature of over $100^{\circ} \mathrm{F}$, (2) a pulse rate greater than 120 per minute, (3) a white cell count of 10000 or more per $\mathrm{mm}$ of peripheral blood, (4) an erythrocyte sedimentation 
stone' appearances were present. Discontinuous disease with skip areas was present in 10 cases; in the other two a continuous pattern was present. The terminal ileum was inflamed in only one case at the time of operation.

\section{MICROSCOPIC APPEARANCES}

In all cases the mucosa and submucosa showed patchy inflammation with fewer crypt abscesses than are usually seen in ulcerative colitis. The inflammatory infiltrate was transmural and tended to follow the course of blood vessels in the muscle coat. In some areas in the transverse colon only there was also patchy muscle coat disintegration such as is seen in toxic dilatation due to ulcerative colitis. Fibrosis was present in the submucosa and subserosa but was markedly less in the transverse colon than in other parts. Fissures into and through the muscle coats were present in all cases, but epithelioid granulomata were present in the bowel wall in only four cases. Only one case showed any significant loss of mucus cells in the glands; mucus cell secretion appeared unimpaired in the remaining eleven.

\section{Discussion}

It is unwise to draw conclusions from a small retrospective series but it is hoped that by attempting to define the condition and report the results of a particular form of treatment that recorded experience will be built up as the condition becomes more widely recognized.

There have been 190 patients treated for Crohn's disease of the large intestine at the Gordon Hospital since 1948, and acute toxic dilatation of the colon has occurred in 12 of them, a rate of $6 \%$. This compares with a rate of $16 \%$ quoted by Farmer et al (1968) for Crohn's disease, and a rate of $1.6 \%$ for the complication in ulcerative colitis reported by Edwards and Truelove (1964).

The clinical profile which emerges is of an uncommon complication of Crohn's disease of the colon affecting predominantly young adult females, with a relatively short preoperative history of the disease.

The best criteria for toxicity appear to be the raised pulse rate, temperature, and ESR; a raised leucocyte count is a less reliable guide, probably because of the suppression of the leucocyte response by steroid therapy.

Abdominal distension before operation and dilatation of the colon at operation were observed in all cases, and a close correlation between these observations and the maximum width of the transverse colon, measured in the fixed state, was found. Unfortunately these findings could not be correlated with preoperative radiological appearances for all the patients, but in the three where radiographs were available there was a good correlation.

All patients in this study underwent total colectomy and ileorectal anastomosis covered by a relieving ileostomy (Aylett, 1970). All were known to have had colitis for at least one month, and in one case 19 years, before operation, but in only one case was a diagnosis of Crohn's disease made preoperatively. This failure to distinguish between Crohn's colitis and ulcerative colitis did not affect the decision to operate on any patient, but the subsequent course taken by many of the patients has been different from patients with acute toxic dilatation complicating ulcerative colitis treated in the same manner (Baker, 1970). The preoperative sigmoidoscopic appearances of the rectum appears to have been of no value in predicting the likelihood of recurrent disease in the region of the anastomosis.

The overall clinical results compare unfavourably with those for total colectomy and ileorectal anastomosis for ulcerative colitis (Aylett, 1970). It is therefore important to recognize that acute toxic dilatation can occur in Crohn's disease as well as in ulcerative colitis from the point of view of prognosis.

\section{PATHOLOGY}

Some of the criteria (Morson and Dawson, 1972) used to distinguish between ulcerative colitis and Crohn's colitis, such as transmural inflammation, vascularity of the mucosa and wall, and serositis, were found to be common to both conditions in the acute toxic, dilated state; however, satisfactory differentiation between the diseases was achieved using the remaining criteria.

Farmer et al (1968) stated that acute dilatation could not occur in Crohn's colitis because of the fibrosis associated with the disease. All our cases showed patchy fibrosis of the submucosa and subserosa, which increased the thickness of the colon wall in all parts except the transverse colon. The reason for this finding is obscure but it may be that the administration of steroids preoperatively delayed the laying down of fibrous tissue in the most severely inflamed area.

The authors wish to thank Mr S. O. Aylett of the Gordon Hospital for permission to publish details of his patients.

Our thanks also to Dr B. C. Morson for critically reviewing the manuscript, to Mrs N. Jackson for typing the manuscript, and to the Department of Photography, Westminster Hospital, for the figure and for table I.

\footnotetext{
References

Aylett, S. O. (1970). Delayed ileorectal anastomosis in the surgery of ulcerative colitis. Brit. J. Surg., 57, 812-813.
} 
Baker, W. N. W. (1970). The results of ileorectal.anastomosis at St. Mark's Hospital from 1953 to 1968. Gut, 11, 235-239.

Brooke, B. N. (1972). Crohn's disease of the large bowel. (Letter) Brit. med. J., 1, 310-311.

Clark, A. W. (1972). Dilatation of colon in Crohn's disease. (Letter) Brit. med. J., 4, 233.

Dawson, I. M. P., and Pryse-Davies, J. (1959). The development of carcinoma of the large intestine in ulcerative colitis. Brit. $J$. Surg., 47, 113-128.

Edwards, F. C., and Truelove, S. C. (1964). The course and prognosis of ulcerative colitis. III. Complications. Gut, 5, 1-15.

Farmer, R. C., Hawk, W. A., and Turnbull, R. B., Jr. (1968). Regional enteritis of the colon: a clinical and pathologic comparison with ulcerative colitis. Amer. J. dig. Dis., 13, 501-514.

Fielding, J. F., and Truelove, S. C. (1972). Crohn's disease of the large bowel. (Letter) Brit. med. J., 1, 310.

Javett, S. L., and Brooke, B. N. (1970). Acute dilatation of the colon in Crohn's disease. Lancet, 2, 126-128.
Leoutsakos, B., and Pedridis, G. (1970). Toxic megacolon complicating Crohn's disease of the colon. Amer. J. Proctol., 21, 258-262.

Lumb, G., Protheroe, R. H. B., and Ramsay, G. S. (1955). Ulcerative colitis with dilatation of the colon. Brit. J. Surg., 43, 182-188.

McGovern, V. J., and Goulston, S. J. M. (1968). Crohn's disease of the colon. Gut, 9, 164-176.

Morson, B. C., and Dawson, I. M. P. (1972). Gastrointestinal Pathology. Blackwell, Oxford.

Papp, J. P., and Pollard, H. M. (1970). Toxic dilatation of the colon in granulomatous colitis. Amer. J. dig. Dis., 15, $1105-1113$.

Roth, J. L. A., Valdes-Dapena, A., Stein, G. N., and Bockus, H. L. (1959). Toxic megacolon in ulcerative colitis. Gastroenterology 37, 239-255.

Schachter, H., Goldstein, M. J., and Kirsner, J. B. (1967). Toxic dilation complicating Crohn's disease of the colon. Gastroenterology, 53, 136-142.

Truelove, S. C., and Witts, L. J. (1955). Cortisone in ulcerative colitis. Brit. med. J., 2, 1041-1048. 